\title{
Pulse-count Distribution as a Possible Diagnostic Tool for Assessing the Level of Degradation of Rotating Machine Insulation
}

\author{
H. N. Geetha, M. B. Srinivas, \\ and T. S. Ramu \\ Dept. HV Engineering, Indian Institute of Science, \\ Bangalore, India.
}

\begin{abstract}
The work covered in this paper pertains to a method by which one can qualitatively assess the condition of epoxy mica insulation systems used in large rotating machines, as function of time. Experimental techniques for acquisition and analysis of failure data have been presented. Experiments have been conducted on actual rotating machine coils subjected to combined electrical and thermal stress, under simulated conditions, so as to reflect the service environment as far as possible. Diagnostic measurements such as incremental loss tangent, capacitance change, partial discharge pulse count/magnitude, and $P D$ energy have been performed along with destructive measurements (dielectric strength). Excellent correlations between pulse count/magnitude and dielectric strength appear to be present. This fact can be used, in the assessment of the degree of degeneration of the insulation.
\end{abstract}

\section{INTRODUCTION}

$\mathrm{T}$

HE conductor insulation in the present day HV rotating machines is composed of mica flakes, bonded by selected solvent-free epoxy resins. Over the years, the manufacturing processes have been continuously upgraded, thereby permitting application of higher electrical, mechanical and thermal stress on turn, conductor, and overhang insulation. The assessment of the integrity of insulation at different points in time during service, and development of a diagnostic test schedule for estimating its longevity have been difficult tasks, requiring serious consideration.

Methods for condition monitoring of generator insula- tion were proposed among others by Kelen [1,2], Schuler and Liptak [3] and Wichmann [4]. Recently, certain aspects of evaluation of elapsed and remaining lives of machine insulation have been reported by Stone and Bernstein [5], and Stone et al. [6], in which doubts have been expressed regarding the reliability of diagnostic test methods themselves and the dependability of the remaining life formulations, suggested by Yoshida and Inoue [7] and Kadotani et al. [8]. The poor correlations between the results of non-destructive tests and destructive tests, such as voltage breakdown, are thought to be the reasons for apprehension expressed by them in applying the remaining life equations in $[7,8]$.

There is an urgent need to define tests and test methods 


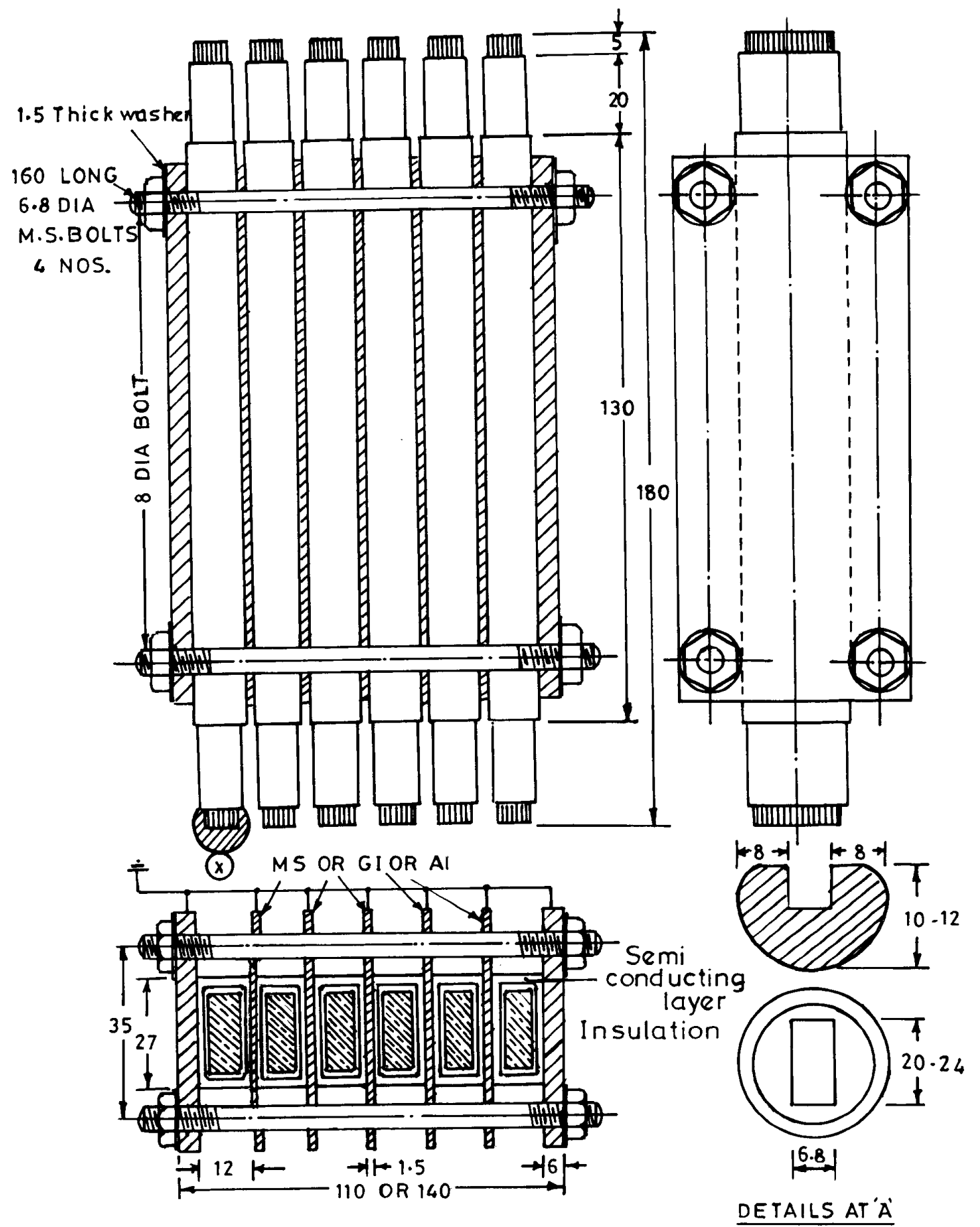

Figure 1. Detailed drawing of specimen assembly (all dimension are in $\mathrm{mm}$, not to scale).

which are capable of faithfully indicating such deleterious changes in the insulation subjected to different stresses, and to be able to draw meaningful conclusions, at least qualitatively, on the state of insulation. Among the more important tests prescribed earlier [1] for solid insulation systems are: 
1. incremental loss tangent $(\Delta \tan \delta)$ and change in capacitance $(\Delta C)$ between two voltage levels $\left(0.2 U_{n}\right.$ and $U_{n}$ where $U_{n}$ is the nominal voltage)

2. the partial discharge (PD) quantities: magnitude, integrated discharge energy per cycle, quadratic rate, pulse height and pulse count

3. polarization index and dc insulation resistance

4. dielectric strength

Obviously, test (4) is destructive and can only be performed on modeled coils or full coils under laboratory conditions.

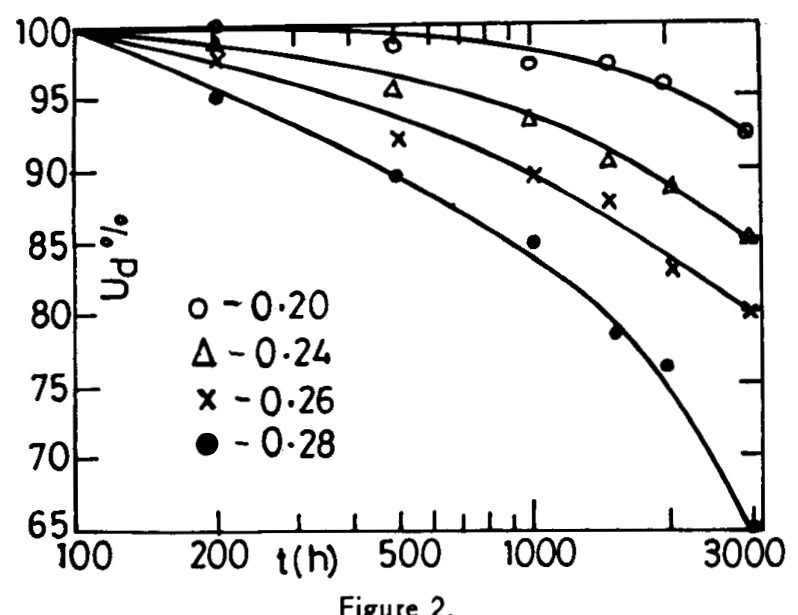

Reduction in breakdown voltage $U_{d}$, with duration of aging time $t$.

The objective of the present work is to establish an acceptable test method which can indicate the condition of insulation, at any point in time, to a reasonable degree of accuracy. In the authors' laboratory, both experimental and analytical work on aging failure of rotating machine insulation are being pursued. Results of recent investigations on epoxy-bonded mica insulation appear to indicate a fair degree of correlation between pulse height and pulse count of internal discharges in insulation and certain other dielectric properties. Among other things, incremental loss tangent and some PD quantities have also been monitored during the course of aging experiments on actual rotating machine coils. The data were analyzed statistically. As the pulse distribution histogram could not always be approximated by known probability density functions, distribution-free methods have been used.

\section{EXPERIMENTAL}

$\mathrm{T}$ HE test specimens were hexagonal rotating machine coils designed for use in a $1 \mathrm{MW}, 6.6 \mathrm{kV}$ motor. The copper conductors were divided into twelve rectangular sections or turns insulated with polyester tape impregnated with a synthetic resin. The ground wall insulation was formed by mica splittings bonded with an epoxy resin (Class F). The average thickness of groundwall insulation was $1.5 \mathrm{~mm}$. Table 1 shows some important properties of the insulation system.

In order to reduce expenses, each coil was cut up into straight sections of $18 \mathrm{~cm}$ each. The outer semiconducting layer of the coil was peeled off to a length of $20 \mathrm{~mm}$, and the insulation around the conductor at the two ends was removed to an extent of $5 \mathrm{~mm}$. Hemispherical aluminum caps fitting tightly onto the copper conductors, were provided so as to suppress corona from the ends of the conductor. Figure 1 shows the detailed drawing of the specimen arrangement. In view of the statistical nature of insulation failure, between six and ten specimens were used for aging at each stress level.

\section{TEST AND TEST METHODS}

A

$30 \mathrm{kV}, 25 \mathrm{kVA} \mathrm{HV}$ transformer was employed for applying electrical stress to the specimens. The thermal stresses were applied by placing the specimens in an oven of which the temperature could be controlled within $\pm 1^{\circ} \mathrm{C}$ to $300^{\circ} \mathrm{C}$. Due to technical and financial constraints, the aging experiments were restricted to about $3000 \mathrm{~h}$ for each run. The electric stresses were chosen so as to give a complete data set in most cases. However, some experiments had to be terminated before all the specimens failed, thus generating censored data.

The dielectric properties of the insulation, both destructive and diagnostic, were measured on a number of specimens at different intervals of time. The time windows, however, were not equal. In the beginning, measurements were made once every week, and during later parts of the aging period, when the insulation was found to have been deteriorated considerably, the measurements were made after every $24 \mathrm{~h}$. The specimens were drawn at random at different intervals over the entire aging period.

The dielectric strengths were observed to follow a twoparameter Weibull distribution. The remaining dielectric strength was taken as the 63.2th percentile of the above distribution. In addition to the remaining dielectric strength, the incremental loss tangent $(\Delta \tan \delta)$, change in capacitance $(\Delta C / C)$, the polarization index $(P I)$ and the PD quantities were measured using standard techniques conforming to relevant standards. 


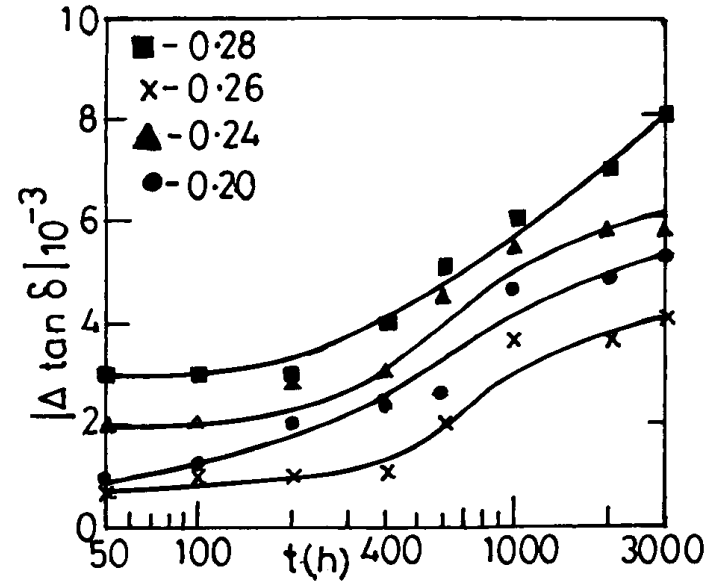

(a)

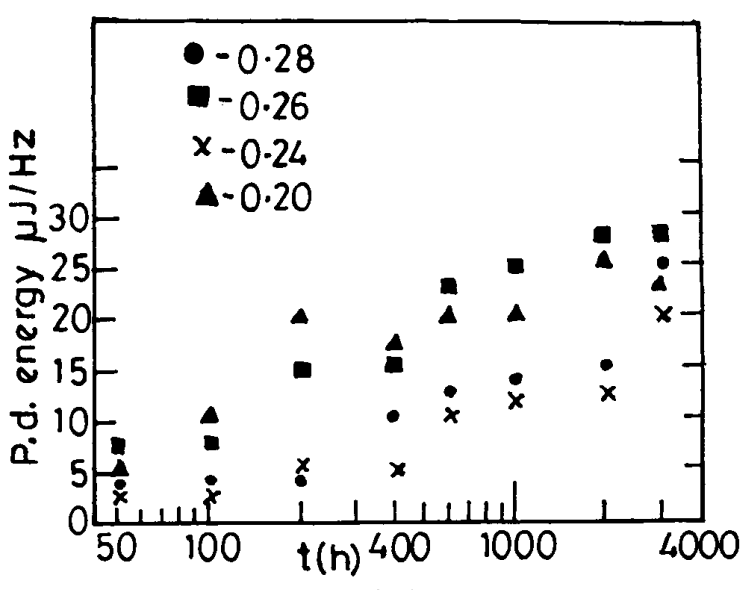

(b)

Figure 3.

Variations in (a): incremental loss tangent $\Delta \tan \delta,(\mathrm{b}): \mathrm{PD}$ energy $/ \mathrm{Hz}$ with duration of aging time $t$

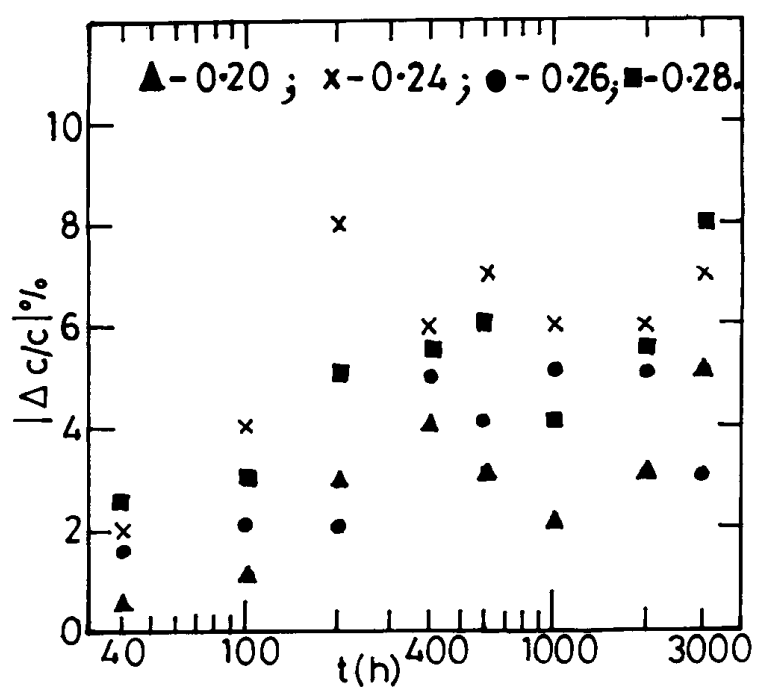

(a)

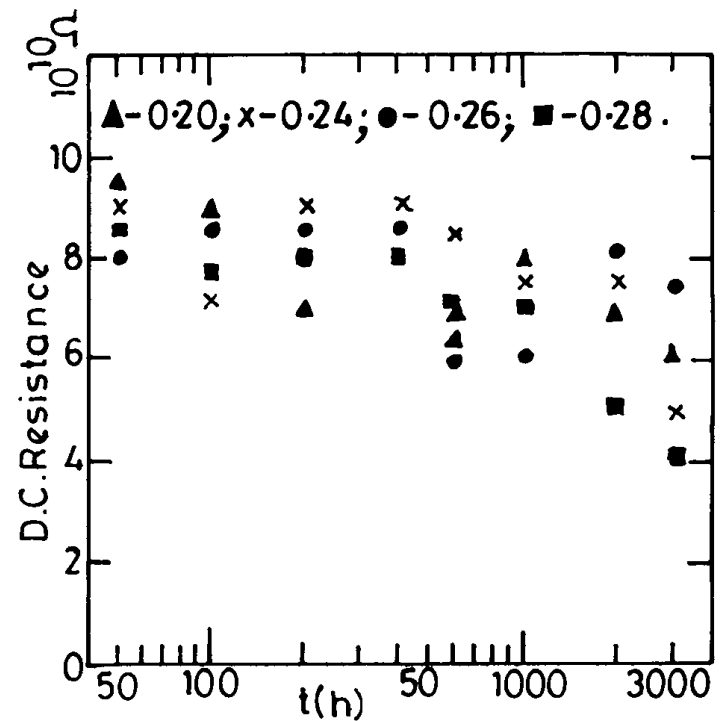

(b)

Figure 4. Variations in (a): change in capacitance $\Delta C / C,(\mathrm{~b}): \mathrm{dc}$ resistance with aging time $t$.

The incremental loss tangent is defined by

$$
\Delta \tan \delta=\left|\tan \delta_{U n}-\tan \delta_{0.2 U n}\right|
$$

where $U_{n}$ is the nominal line to ground voltage of the insulation system. The change in capacitance $(\Delta C / C)$ is defined by

$$
\frac{\Delta C}{C}=\frac{C_{0}-C_{t}}{C_{0}}
$$

where $C_{0}$ is the capacitance at time $t=0$, and $C_{t}$ is the capacitance at time $t$.

The capacitance and loss tangent at power frequency voltage were measured with a transformer ratio arm bridge (Tettex model 2805), in conjunction with a standard 100 pF, $300 \mathrm{kV}$ compressed nitrogen capacitor (GE number 265 2835). The polarization index was measured using a $1 \mathrm{kV}$ stabilized dc source along with a current/ voltmeter (Philips model GM6020). The PD measurements were made with a commercial PD detector (ERA model 5) and a discharge-free blocking capacitance ( 4400 $\mathrm{pF}$ ). The pulse magnitude and counts were made with a four-channel digital counter (ECIL model 5104), capable of discriminating between two pulses appearing within a 


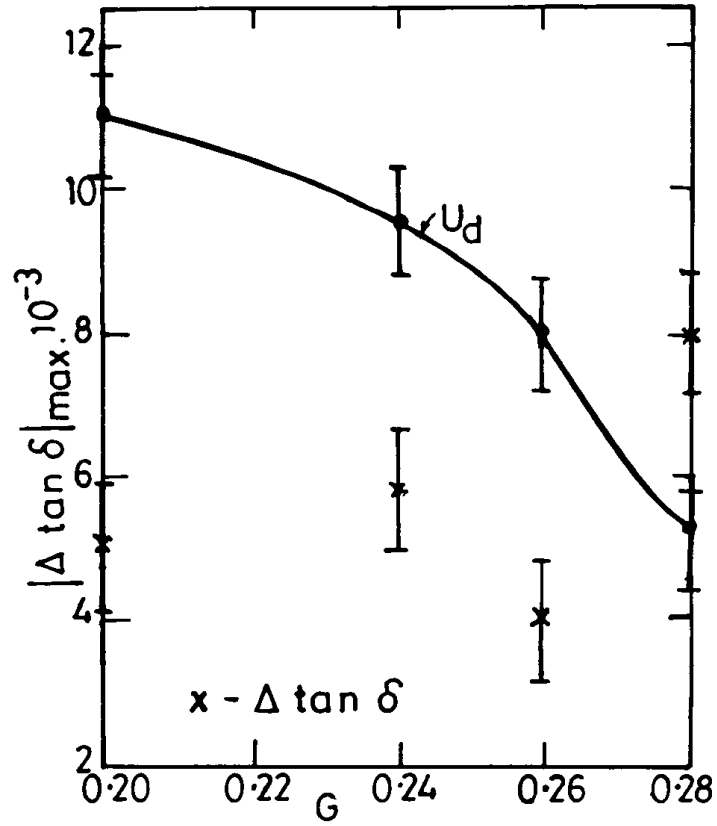

(a)

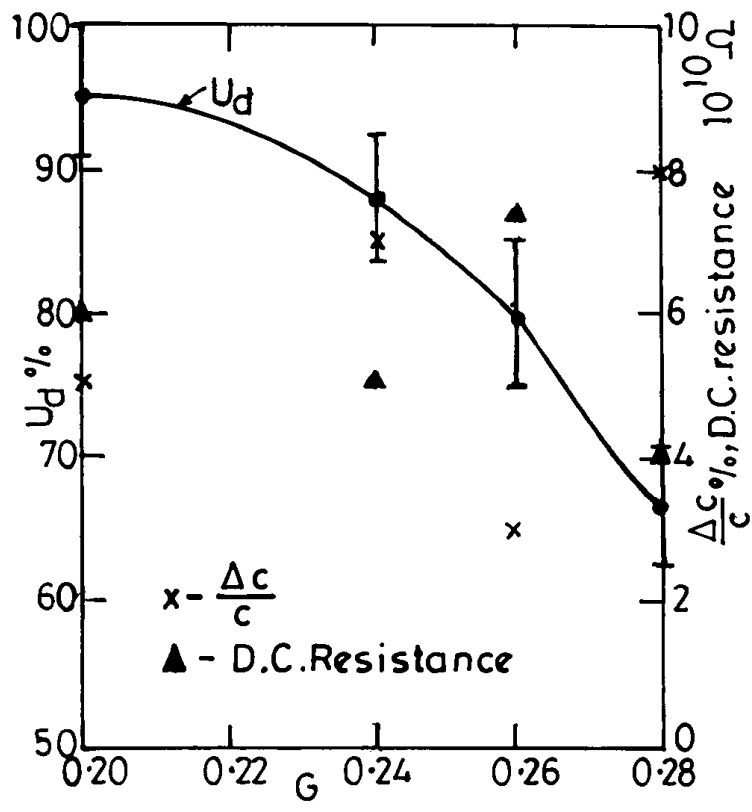

(b)

Figure 5.

Changes in $\Delta \tan \delta, \Delta C / C$, dc resistance and $U_{d}$ with stresses applied during aging $(t=3000 \mathrm{~h})$

time frame of $1 \mu \mathrm{s}$. Both positive and negative voltage pulse counts have been recorded along with their amplitudes. The PD energy was then calculated as follows: If $Q=$ total charge, $C=$ specimen capacitance and $n_{i}$, the number of pulses with amplitude $U_{i}$, then

$$
\begin{aligned}
Q & =C U \\
Q & =\sum Q_{i}=C \sum n_{i} U_{i} \\
E_{p d} & =\frac{1}{2} C \sum\left(n_{i} U_{i}^{2}\right)
\end{aligned}
$$

\section{RESULTS}

$\mathrm{T}$

HE results of the investigations and their analysis are $\mathcal{L}$ presented separately. Figure 2 depicts the breakdown voltage, $U_{d}$ as a function of duration of aging. In Figures 3 and 4 , the diagnostic properties, $\Delta \tan \delta, P D$ energy per cycle, $\triangle C / C$ and dc resistance are plotted as functions of the duration of aging. Electric stresses applied during aging are expressed by a stress factor $G$, defined as the ratio of aging stress to dielectric strength of the unaged specimens. The range of $G$ used was between 0.2 and 0.28 . The temperature was maintained constant at $100^{\circ} \mathrm{C}$ during aging. Both complete and truncated data arising out of the experiments were analyzed using the methods described in [9].
The percentage residual dielectric strengths $U_{d}, \Delta \tan \delta$, $\Delta C / C$ and dc resistance, after $3000 \mathrm{~h}$ of aging are shown in Figure 5 as function of aging stresses $G$. Values of $U_{d}$ are characterized by a considerable degree of scatter and this is indicated by the scatter bar having a width of twice the standard deviation. The scatter in the diagnostic measurements is shown wherever necessary.

\section{ANALYSIS}

$\mathrm{T}$

HE statistical distribution functions, cumulative probability $F(x)$, and probability density, $f(x)$ of the positive and negative pulse counts of different magnitudes are depicted in Figures 6 to 9 for 500, 1500, 2500 and $3000 \mathrm{~h}$ of aging, respectively. The probability densities did not conform to any known specific distribution. The statistical quantities such as mean, standard deviation, skewness and kurtosis of pulse distribution were calculated and are presented in Table 2. It is important to note that a sufficient number of decimal places is required to be carried through in the computations, particularly for skewness.

It is suggested that double precision mode be used in the calculations of skewness. While plotting, however, the Figures are rounded off to appropriate decimal places. In Figure $10, U_{d}$, PD energy per cycle and skewness of positive pulses are plotted as functions of $G$, after $3000 \mathrm{~h}$ 


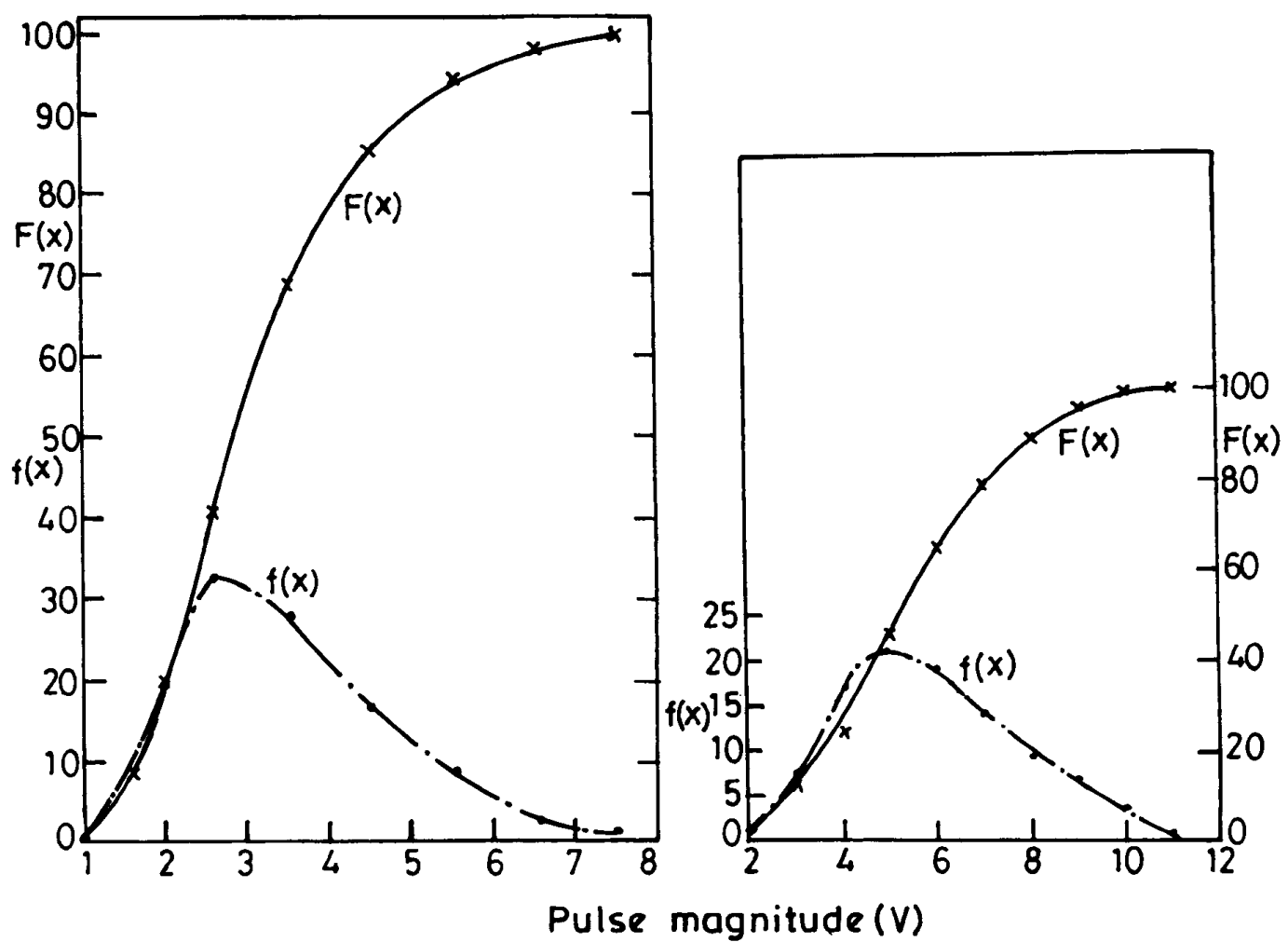

(a)

(b)

Figure 6. Statistical distribution of positive pulse counts after (a): $500 \mathrm{~h},(\mathrm{~b}): 1500 \mathrm{~h}$ of aging.

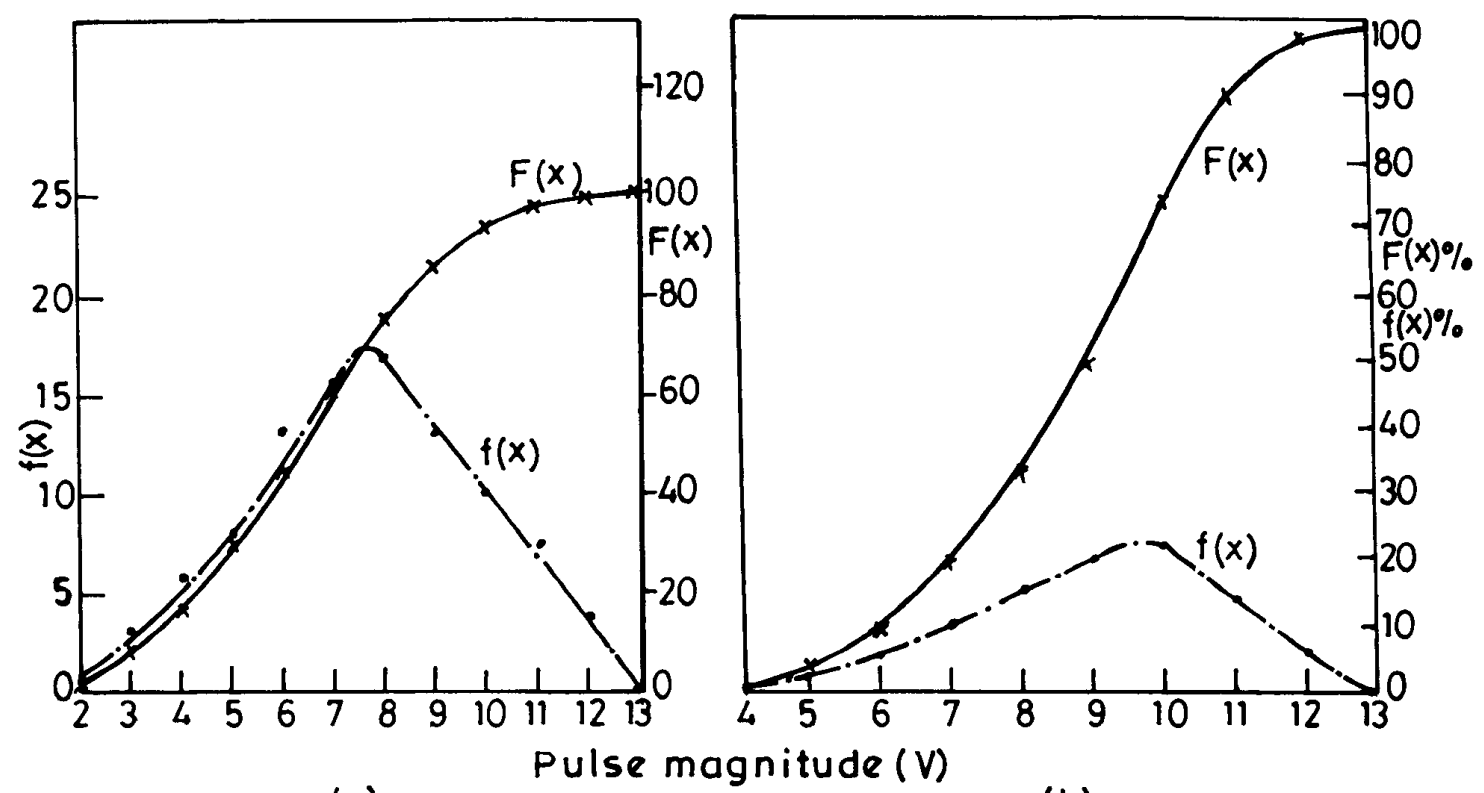

(a)

(b)

Figure 7. Statistical distribution of positive pulse counts after (a): $2500 \mathrm{~h},(\mathrm{~b}): 3000 \mathrm{~h}$ of aging.

of aging. Figure 11 depicts the change in skewness as a function of the duration of aging at $G=0.28$, as an exam- 


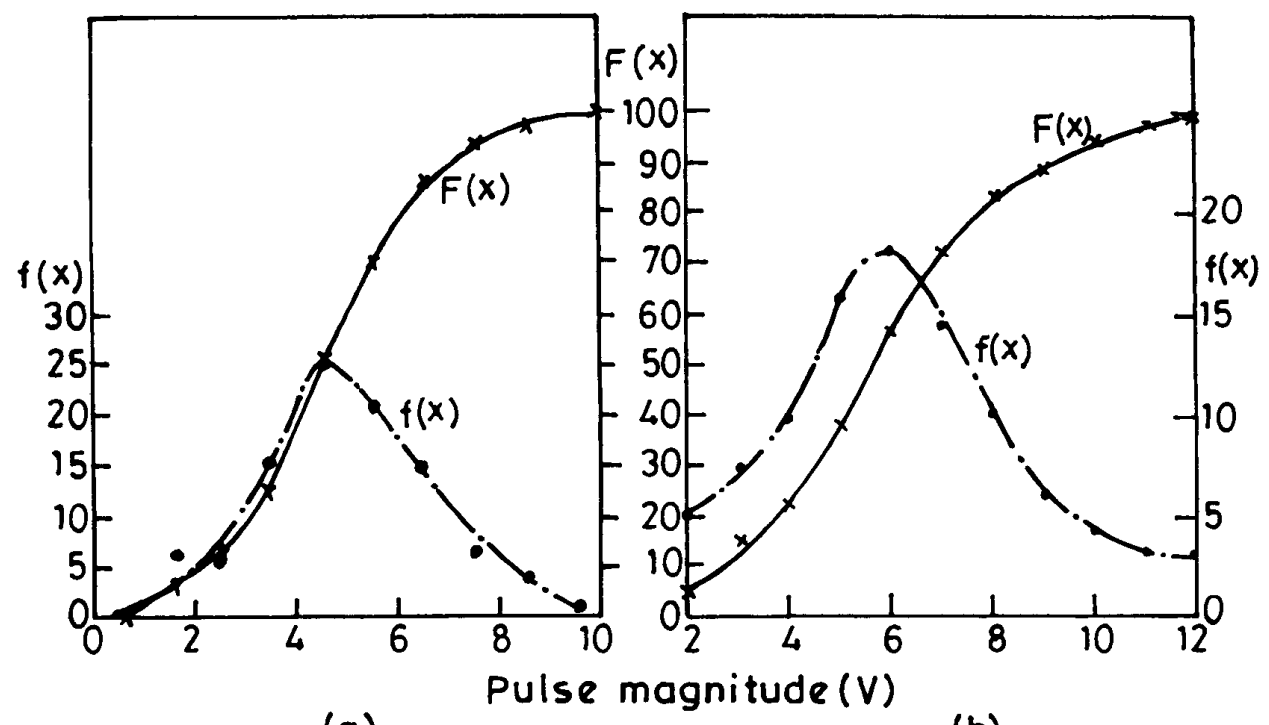

(a)

(b)

Figure 8. Statistical distribution of negative pulse counts after (a): $500 \mathrm{~h},(\mathrm{~b}): 1500 \mathrm{~h}$ of aging.

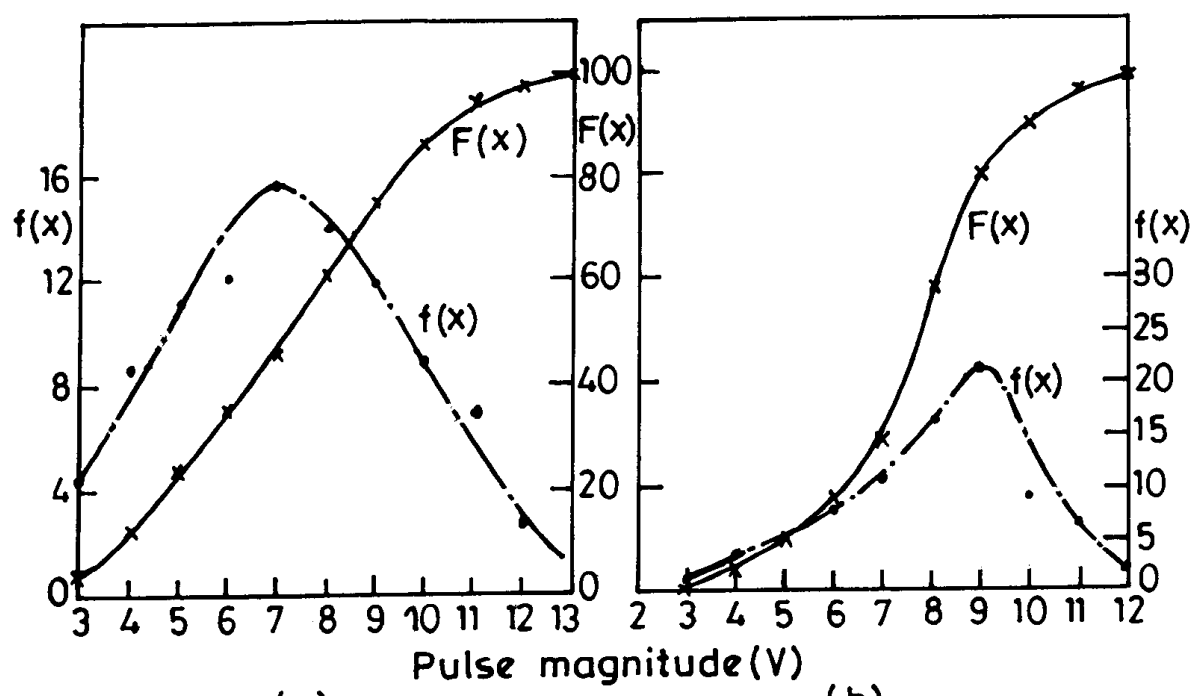

(a)

(b)

Figure 9. Statistical distribution of negative pulse counts after (a): $2500 \mathrm{~h}$, (b): $3000 \mathrm{~h}$ of aging.

ple. Similar results were obtained for other stress factors, and for negative pulse counts also. Table 3 covers the coefficients of correlation between the several diagnostic properties themselves, the stress factors used, the skewness and the dielectric strength.

\section{DISCUSSION}

TELEN has listed a number of diagnostic tests and com1 pares them based on their 'revealing power'. This term is abstract in that it can only be represented in arbitrary units and acquires a more definite meaning only when a destructive property like $U_{d}$ is associated with it. For quite some time now, the incremental loss tangent (or loss tangent tip up) and increase in integrated discharge energy per cycle were thought to be indices of failure or impending hazard. It is true that each one of the properties measured gives valuable information on the status of insulation but the connections between the amount of insulation degradation and the diagnostic properties (or between the diagnostic measurements and the dielectric 


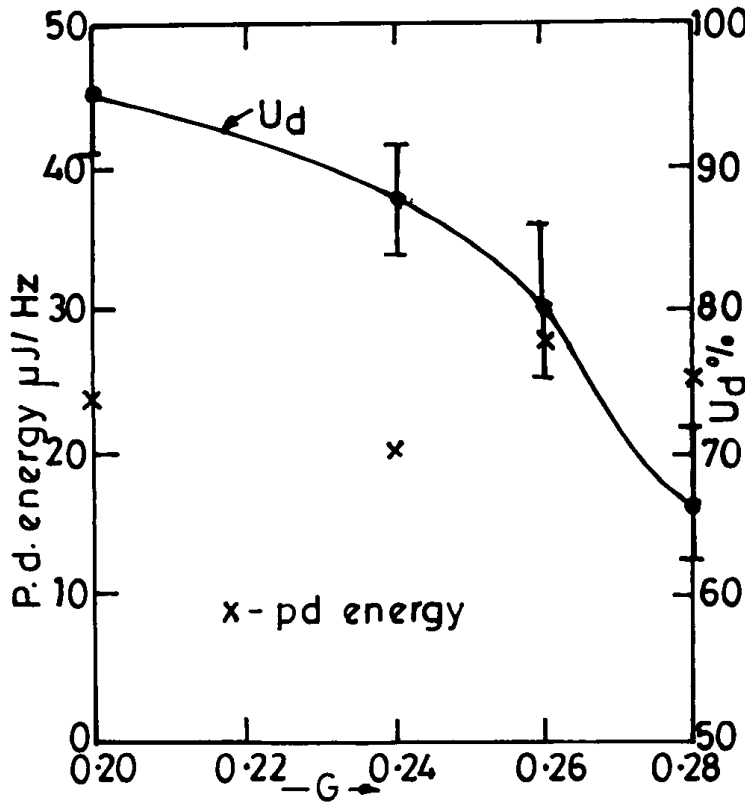

(a)

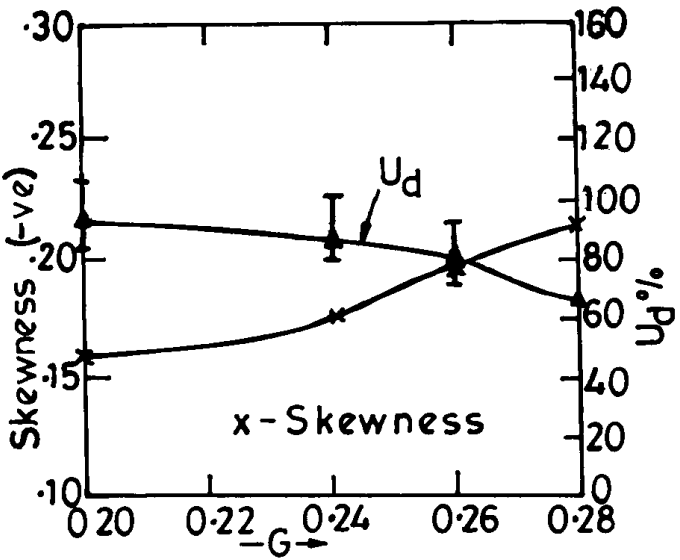

(b)

Figure 10.

Changes in $\mathrm{PD}$ energy $/ \mathrm{Hz}$, skewness and $U_{d}$ with stresses applied during aging $t=3000 \mathrm{~h}$.

strength) are not always quantitative.

Table 1.

Dielectric properties of epoxy bonded mica insulation

\begin{tabular}{lcl}
\hline \hline Permittivity & 4.6 & \\
Dissipation factor & $\approx 10^{-2}$ & \\
(room temp., 50 Hz) & & \\
Volume resistivity & $10^{16}$ & $\Omega \mathrm{cm}$ \\
Electric strength & $22-25$ & $\mathrm{kV} / \mathrm{mm}$ \\
(room temp., $50 \mathrm{~Hz}$ ) & & \\
\hline \hline
\end{tabular}

Some results on $\mathrm{PD}$ measurements on insulation specimens containing voids (created deliberately in the body of plain epoxy) are presented by Tanaka and Okamoto [10]. The pulse angle and height and the 'aspect' ratio are qualitatively related. Their analysis, however, does not suggest any functional relationship between the pulse distribution parameters and the diagnostic properties. Kelen [2] has also described a diagnostic test for generator insulation subjected to higher frequencies, vibration and thermal cycling. The plane-parallel specimens with voids of predetermined geometries are used in this study. Pulse magnitude/count distribution study also forms a part of this work. Some discussion on the correlation between the

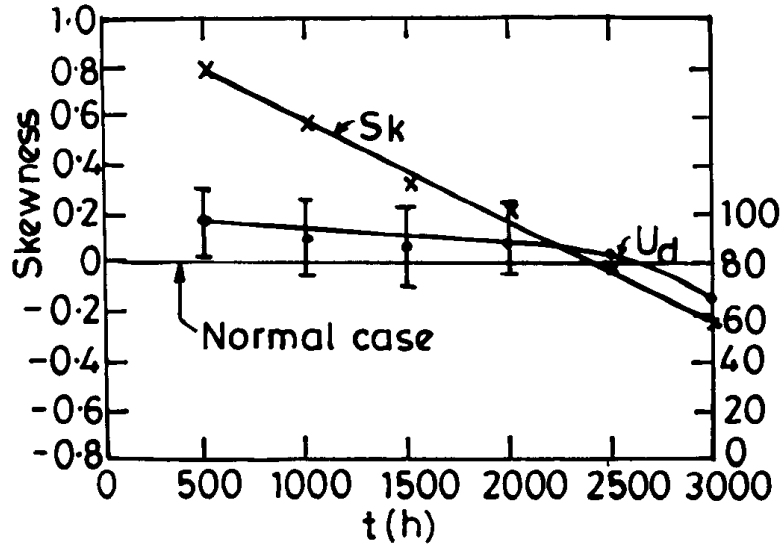

Figure 11.

Variation in skewness and $U_{d}$ as a function of aging time for $G=0.28$.

pulse magnitude studies and a few other dielectric properties are included, and a fair degree of correlation between loss tangent tip-up and pulse magnitude distribution has been reported in his paper. However he concludes that a definite indication of the amount of degradation is given only by destructive measurements. No details on the statistical analysis of pulse count data are given. 
Table 2.

Estimated values of statistical parameters of positive and negative pulse magnitude distribution at different aging intervals $(G=0.28)$

\begin{tabular}{|c|c|c|c|c|c|c|c|c|}
\hline \multirow{3}{*}{$\begin{array}{l}\text { Statistical } \\
\text { Parameters }\end{array}$} & \multicolumn{8}{|c|}{ Duration of aging $(\mathrm{h})$} \\
\hline & \multicolumn{2}{|c|}{500} & \multicolumn{2}{|c|}{1500} & \multicolumn{2}{|c|}{2500} & \multicolumn{2}{|c|}{3000} \\
\hline & + & - & + & - & + & - & + & - \\
\hline$\mu$ & 3.55 & 5.06 & 6.00 & 6.30 & 7.73 & 6.91 & 9.06 & 7.65 \\
\hline$\sigma^{2}$ & 1.72 & 3.35 & 3.62 & 5.63 & 5.28 & 5.98 & 3.26 & 3.47 \\
\hline$\sigma$ & 1.31 & 1.83 & 1.90 & 2.37 & 2.30 & 2.45 & 1.81 & 1.86 \\
\hline$S_{k}$ & 0.74 & 0.77 & 0.39 & 0.36 & 0.04 & 0.01 & -0.21 & -0.30 \\
\hline$K$ & 3.33 & 2.79 & 2.63 & 2.79 & 2.49 & 2.23 & 2.53 & 3.22 \\
\hline & reig & ed $n$ & $\begin{array}{l}\text { ean } \\
\text { e }(m\end{array}$ & pulse & $\begin{array}{l}\text { nagn } \\
K=\end{array}$ & itud & $\begin{array}{l}(\mathrm{mV}) \\
\text { is; } \\
\text { ewness }\end{array}$ & \\
\hline
\end{tabular}

Table 3

Coefficient of correlation between diagnostic properties, breakdown voltage, $U_{d}$ and the stress factor $G$

\begin{tabular}{|cccccccc|}
\hline \hline Parameter & $\bar{G}$ & $\Delta \tan \delta$ & $\Delta \bar{C} / \bar{C}$ & $\bar{E}_{P D}$ & $\overline{R_{d c}}$ & $U_{d}$ & $S_{k}$ \\
\hline$G$ & - & 0.4483 & 0.2861 & 0.4692 & -0.2778 & -0.9429 & -0.9472 \\
$\Delta \tan \delta$ & 0.4483 & - & 0.9282 & -0.2210 & -0.9556 & -0.6462 & -0.5725 \\
$\Delta C / C$ & 0.2861 & 0.9282 & - & -0.5509 & -0.9943 & -0.4181 & -0.3249 \\
$E_{P D}$ & 0.4692 & -0.2210 & -0.5509 & - & 0.4971 & -0.4845 & -0.5678 \\
$R_{d c}$ & -0.2778 & -0.9556 & -0.9943 & 0.4971 & - & 0.4412 & 0.3505 \\
$U_{d}$ & -0.9429 & -0.6462 & -0.4181 & -0.4845 & 0.4412 & - & 0.9949 \\
$S_{k}$ & -0.9472 & -0.5725 & -0.3249 & -0.5678 & 0.3505 & 0.9949 & - \\
\hline \hline
\end{tabular}

Empirical relationships between diagnostic properties and dielectric strength have been suggested by Japanese authors $[7,8]$. Contradictions to these findings have been expressed by Stone et al. [6] based on extensive work on both generator and motor insulation. Stone et al. did not find a correlation between the dielectric strength and other dielectric properties.

Table 3 shows that there is consistently a very high level of correlation between some diagnostic properties and very poor level of correlation in some others. dc resistance and $\Delta C / C, \Delta \tan \delta$ and $\Delta C / C$ are well correlated. Strong correlation observed between the dielectric strength and the skewness is discussed below.

While the dielectric properties were being measured during the course of aging, it was observed that both the positive and negative pulse count/magnitude data could be statistically treated by approximating the discrete data into smooth unimodal density functions.

A second and a more interesting observation made was that, when the probability densities were plotted at the beginning of the aging period, the distributions were skewed to the left. As aging progressed the skewness approached zero. Further aging would make the density function skewed to the right. Failure invariably occurs after this condition is reached. It was therefore decided to use skewness as a possible parameter for indicating the amount of aging. The correlation coefficient between the skewness and the loss of dielectric strength was very high $(>0.9)$, see Table 3 .

The physical implication of this fact is that, as the damage accumulates, the number of discharge sites in the body of the insulation such as crevices, tree-like breakdown paths, and micro cracks grows. As a consequence, the number density of discharge pulses increases and the maximum amplitude of discharges also increases. This is borne out by the fact that the weighted mean amplitude as well as the modal value of the distributions shown in Figures 6-9 increase in step. It is observed from these Figures that the skewness which was positive in the beginning goes over to zero, and later on, the coefficient of skewness becomes negative. The dielectric strength decreases with increased aging. Therefore a strong correlation exists between the skewness of the density function of pulse distribution and the dielectric strength. Figures 
10 and 11 vividly bring out the excellent correlation between $U_{d}$ and skewness as a function of aging time and the stress factors.

We should emphasize that all our experiments were formed under well-controlled laboratory conditions. This perhaps is the reason for good repeatability of measurements and high correlation between dielectric strength and pulse distribution measurements. However, in a practical situation (where dielectric strength measurements cannot be performed) the pulse height and count distribution studies would give a qualitative estimate of loss of life. Recently, work on the estimation of elapsed life of machine coils in actual service has been started. The results would accrue in one or two years from now, after which it may be possible to establish a three-way functional relationship between the loss of dielectric strength of coil insulation, the pulse distribution results and the time to failure.

In conclusion, the work covered in this paper enables one to assess, at least qualitatively, the state of insulation at any point in time by making diagnostic measurements, particularly pulse height distribution studies.

\section{REFERENCES}

[1] A. Kelen, "Diagnostics of HV Machine Insulation From Inspection to continuous monitoring", CIGRE Symposium, Vienna, paper 5-87, 1987.

[2] A. Kelen, "The Functional testing of HV Generator Stator Insulation", CIGRE, Vol. 1, paper 15-03, 1976.
[3] R. H. Schuler, and G. Liptak, "Long time functional tests on insulation systems for HV rotating machines", CIGRE, Vol. 1, paper 15-05, 1976.

[4] A. Wichmann, "ac and dc methods for the evaluation and maintenance testing of $\mathrm{HV}$ insulation in electrical machines", IEEE Trans. on Power App. and Syst., Vol. 82, pp. 273-281, 1963.

[5] G. C. Stone, and B. S. Bernstein, "Toward assessing the remaining life of rotating machine insulation", IEEE Conf. on Electrical Insulation, pp. 71-75, 1987.

[6] G. C. Stone, H. G. Sedding, B. A. Lloyd, and B. K. Gupta, "The ability of diagnostic tests to estimate the remaining life of stator insulation", IEEE Trans. on Energy Conversion, Vol. 3, No. 4, pp. 833-840, Dec. 1988.

[7] H. Yoshida, and Y. Inoue, "Test methods of Rotating Machines", IEEE Trans. on Electrical Insulation, Vol. 21, pp. 1069-1071, 1986.

[8] K. Kadotani, T. Hakamada, and S. Yamatake, "A proposal for insulation diagnosis of $3 \mathrm{kV}$ motor Stator windings", IEEE Trans. on Electrical Insulation, Vol. 18, pp. 59-63, 1983.

[9] T. S. Ramu, "On the estimation of life of power apparatus insulation under combined electrical and thermal stress", IEEE Trans. on Electrical Insulation, Vol. 20, pp. 170-178, 1985.

[10] T. Tanaka, and T. Okamoto, "An advanced PD measurement method sensitive to the shape of a void", CIGRE, preferential subject 2, paper 15-02, 1988.

Manuscript was received on 11 May 1989, in revised form 18 Apr 1990. 